\title{
Avaliação da Satisfação de Formandos de um Curso de Graduação em Administração de uma Faculdade Pública Paulista
}

\author{
Luciana Manzan Ferreira*, Valquíria Monteiro dos Santos*, André Lucirton Costa* \\ *Faculdade de Economia, Administração e Contabilidade de Ribeirão Preto da Universidade de São Paulo
}

* Autores para correspondência: lumanzan@fearp.usp.br; valquiria@fearp.usp.br; alcosta@fearp.usp.br

\begin{abstract}
RESUMO
Esta pesquisa buscou investigar a satisfação dos alunos formandos de um curso de graduação em Administração de uma universidade pública do Estado de São Paulo. Trata-se de um estudo quali-quantitativo com dados coletados por meio de questionário aplicado a alunos. Os formandos respondentes avaliaram que os professores, em geral, têm um domínio alto do conteúdo das disciplinas e abrem espaço para discussão; ressaltaram, porém, que, para muitos, faltam didática e estratégias inovadoras. Na média, o envolvimento de docentes com o aluno é considerado baixo. A pesquisa abordou a contribuição para a formação pessoal e profissional dos discentes, a melhoria da capacidade analítica dos alunos durante o curso, bem como a interdisciplinaridade. A importância do relacionamento entre professores e estudantes para o desenvolvimento do curso também foi abordada e, diante de alguns aspectos contraproducentes apontados pelos formandos, verificou-se a necessidade de criação de novas estratégias de ensino e ações de melhoria que contribuam para a qualidade do curso.
\end{abstract}

Palavras-chave: Avaliação; Satisfação; Curso de Graduação.

\begin{abstract}
This research aimed to investigate the satisfaction of graduating students in Business Administration, in a public faculty in São Paulo state. It is a quali-quantitative study with data collected through a questionnaire applied to students. The respondents evaluated that teachers generally have a high command in the content of disciplines and open space for discussion; however, for many, there is a lack of didactic and innovative strategies. On average, the involvement of teachers with the student is considered low. The survey addressed the contribution to personal and professional development of students, improving the analytical capacity of the students during the course, as well as interdisciplinary. The importance of the relationship between teachers and students for the development of the course was also the addressed and, before some counterproductive aspects pointed out by respondents students, there was the need to create new teaching strategies and improvement actions that contribute to the quality of the course.
\end{abstract}

Keywords: Assessment; Satisfaction; Graduation Course.

\section{Introdução}

A avaliação da satisfação dos serviços é um dos principais pontos para a melhoria contínua das organizações. A partir do levantamento das percepções e experiências vividas pelos usuários, é possível absorver informações significativas que poderão nortear decisões de planejamento para incrementar a qualidade oferecida pelo serviço.

O serviço educacional prestado por uma Instituição de Ensino Superior (IES) deve ser constantemente avaliado, com o intuito de identificar falhas e propor melhorias. Segundo Melo, Dutra e Oliveira (2001), as motivações para se fazer avaliação de uma IES podem estar relacionadas a aspectos desde a utilização de recursos até as dimensões administrativa e pedagógica.

Nesse sentido, as informações prestadas por formandos de cursos de graduação podem trazer contribuições sobre o conteúdo oferecido e o modelo de interação que ocorre na IES (SOUZA et al., 2014).

A IES analisada foi criada nos anos 1990 e teve gestão autônoma uma década depois. Entre 
outros cursos, oferece o de graduação em Administração, e conta com programas de pós-graduação stricto sensu e cursos de especialização (MBAs) em diversas áreas. Atualmente, o referido curso conta com aproximadamente quarenta professores doutores e mais de quinhentos alunos, com carga horária total de 3.780 horas.

Trata-se de uma escola bem-conceituada internacionalmente, que preza pela satisfação dos alunos no sentido de que suas necessidades sejam amplamente atendidas. É uma instituição rica pela diversidade cultural de alunos oriundos de diversas regiões do país. Da mesma maneira, a universidade na qual está inserida, tradicionalmente reconhecida pela pesquisa e ensino de qualidade, busca aprimorar sua excelência ao longo dos anos. Dessa forma, avaliar a satisfação dos alunos com o curso de Administração da referida escola faz-se necessário, uma vez que a sociedade caminha para o desenvolvimento de maneira progressiva e acelerada.

Partindo da premissa de que um processo de gestão na universidade pública só se faz com grande apoio da comunidade e, diante da relevância da busca incessante pela melhoria do ensino de graduação, houve a necessidade de responder à seguinte questão norteadora: Qual o grau de satisfação dos alunos formandos do curso de Administração da faculdade analisada?

Explorando esse contexto, o objetivo deste artigo é mensurar a satisfação dos formandos do curso de graduação em Administração de uma IES pública, com o intuito de traçar ações estratégicas de melhoria no ensino e atendimento aos alunos do curso.

\section{Satisfação em Instituições de Ensino}

Discutiu-se a importância do tema tendo como base pesquisas de satisfação apresentadas em artigos que apontam: 1) de acordo com Santos, Anjos e Almeida (2013), os formandos consideram haver déficit de metodologias de ensino e de práticas pedagógicas de professores; 2) falta de incentivo à iniciação científica e à produção de pesquisas; e 3. segundo Salles et al. (2013), a qualidade do corpo docente é um aspecto muito importante na avaliação dos cursos.

$\mathrm{O}$ processo de ensino-aprendizagem visto da óptica discente deve ser valorizado (LOUSADA \& MARTINS, 2005), uma vez que a construção do saber é uma via de mão dupla em que aluno e professor devem estar em sintonia, para que o conteúdo proposto seja absorvido com sucesso e futuramente aplicado no mercado de trabalho ou na vida social do aluno. Nesse sentido, teoria e prática se alinham na vida acadêmica e profissional do discente.

No caso do aluno de graduação em Administração, espera-se que ele adquira com o aprendizado uma práxis reflexiva, de modo a que a teoria sirva de norte para sua conduta no mundo dos negócios (MELLO et al., 2001).

Com a evolução da sociedade que chega à era digital com sede de dinamismo, algumas práticas docentes tornam-se pouco eficientes à medida que o aluno traça suas expectativas em relação ao curso escolhido. Diante desse contexto, é preciso mensurar a satisfação do aluno em diversos atributos (MAINARDES \& DOMINGUES, 2011) e periodicamente, para que sua opinião seja não apenas conhecida, mas valorizada, refletindo-se no tipo de sociedade que estamos formando. Se o aluno deve ser transformado em um ser reflexivo em uma época de acúmulo de informações, precisamos ouvi-lo.

A sociedade da informação é uma realidade decorrente dos novos mercados, meios de comunicação e consumidores desta era que conseguiu transformar o mundo em uma grande sociedade globalizada e globalizante, na qual os bens primordiais são informação e conhecimento (CRUZ, 2008).

Cada docente naturalmente tem seu estilo e modo de ensino. Ainda que as ferramentas utilizadas sejam as mesmas, a didática adotada pode ser diferente. Faz-se necessário que o corpo docente entenda a geração para a qual está ensinando e se adapte a ela, de maneira que o ensino vá ao encontro das expectativas atuais. $\mathrm{O}$ 
docente deve procurar metodologias inovadoras para aplicá-las em suas disciplinas (MELLO et al., 2014).

Uma vez satisfeito, no tocante ao aprendizado, o aluno é naturalmente incentivado a refletir, pesquisar e produzir (SANTOS et al, 2013). Traça-se um processo espontâneo que muito contribui para a iniciação científica.

A forma tradicional de conhecimento presente nas escolas centrava-se na figura do professor, sendo este tratado como o "dono do saber". Hoje, percebemos mudanças nesse cenário. $\mathrm{Na}$ era da informação, o espaço de saber do docente foi dando lugar ao de mediador e problematizador do aprender: ele passou a ser visto como aquele que desafia os alunos, mostrando-lhes, entre as várias possibilidades de aprendizagem, caminhos que poderão ser percorridos (CRUZ, 2008).

Assim, novas estratégias de ensino-aprendizagem precisam ser adotadas com o passar dos anos (GRUZ, 2008). Um docente que se formou há uma ou duas décadas não pode adotar o mesmo sistema de ensino da época em que ele começou a ministrar aulas. Assim, cabe à escola ajudá-lo na leitura do novo aluno, para que, ainda que ao seu modo, o docente possa transferir o que sabe estrategicamente, prevalecendo a boa didática, que é aquela em que o professor ensina e o aluno realmente aprende. $\mathrm{O}$ aluno será um formando satisfeito e apto a buscar novos conhecimentos que possam aprimorar o que ele já aprendeu.

\section{Método}

O estudo é caracterizado como uma pesquisa descritiva quali-quantitativa, utilizando-se o questionário como instrumento para a coleta de dados, que contou com questões abertas, outras baseadas na escala de Likert de cinco pontos e também questões dicotômicas. O questionário conta com seis blocos de perguntas: professores (domínio sobre o conteúdo, didática, avaliações, estratégias utilizadas); conteúdo (associação de conceitos relevantes, aprendizado, conteúdos abordados); alunos (dedicação do aluno, relacionamento com os colegas e com o professor, dedicação à disciplina); estrutura (volume de atividades, ferramentas, instalações físicas, material didático); coordenação e direção (atuação da chefia, coordenação e funcionários); aspectos gerais (qualidade do ensino e comentários gerais).

A pesquisa procurou avaliar basicamente três processos: o ensinar, envolvendo aspectos como a didática e o conhecimento dos professores, o conteúdo das disciplinas, os alunos e a estrutura oferecida pela faculdade; o coordenar, que se refere ao modo como a graduação é gerida; e o geral, que engloba todos os demais aspectos envolvidos no curso.

Nas escalas foram abordados diversos itens, em que cada respondente deveria atribuir nota numa escala crescente de satisfação/concordância variando entre 0 e 5 .

Os dados foram coletados nos meses de novembro e dezembro de 2014, por meio de um questionário eletrônico, cujo link foi divulgado por e-mail, tendo como população 78 alunos cursando o último semestre do curso de Administração da IES em questão. Ainda que a divulgação do questionário tenha sido enviada aos alunos em três momentos diferentes, a amostra foi composta de 24 alunos, um número suficiente para embasar a pesquisa.

O questionário já havia sido aplicado aos alunos formandos em anos anteriores, verificando-se a importância da continuidade da pesquisa. As questões foram elaboradas e recanalizadas pela coordenação do curso, que identificou a necessidade de aplicação aos formandos para melhoria do curso de Administração avaliado. Houve a assessoria da secretaria do curso na divulgação e aplicação do questionário, bem como na tabulação e compilação dos dados.

$\mathrm{Na}$ análise dos dados, as informações coletadas foram tabuladas em planilha do Excel e, posteriormente, elaboraram-se histogramas. Dessa forma, foi possível atrelar as informações obtidas nas respostas abertas às apreendidas nos testes baseados em escala, e às das questões di- 
cotômicas, obtendo-se uma avaliação qualitativa dos resultados.

O processo de pesquisa ocorreu primeiramente com a escolha do tema, que surgiu com a percepção da coordenação do curso quanto à necessidade de conhecer a opinião daqueles que passaram cinco anos, ou mais, vivenciando o curso em suas diversas atividades.

A combinação de diversos tipos de questões possibilitou que os formandos pudessem expressar melhor suas percepções sobre o curso.

\section{Resultados e Discussão}

Os resultados obtidos com a pesquisa entre os formandos foram divididos de acordo com cada bloco de questões, nos seis quesitos investigados. Utilizaram-se diversos atributos, pela importância de sua diversificação (MAINARDES \& DOMINGUES, 2011).

\section{Professores}

Conforme demonstra o Gráfico 1, verificou-se que os professores, em geral, têm um alto domínio sobre o conteúdo das disciplinas e abrem espaço para discussão. Porém, para muitos, falta uma didática mais sensível às necessidades e expectativas dos discentes, bem como estratégias inovadoras na atuação docente. Na média, o envolvimento de docentes com o aluno é considerado baixo, fator que pode prejudicar o processo de ensino-aprendizagem.

Quanto ao domínio na área em que atuam, foram citados 79\% dos docentes do departamento, enquanto $33 \%$ foram mencionados na questão "Quais professores não têm domínio na área em que atuam?". Um dos docentes do curso se destacou, sendo citado por $21(88 \%)$ dos respondentes, como um professor "com domínio na área em que atua".

Quanto aos docentes com ótima didática, 54\% foram citados. Entre as estratégias didáticas utilizadas

\section{Professores}

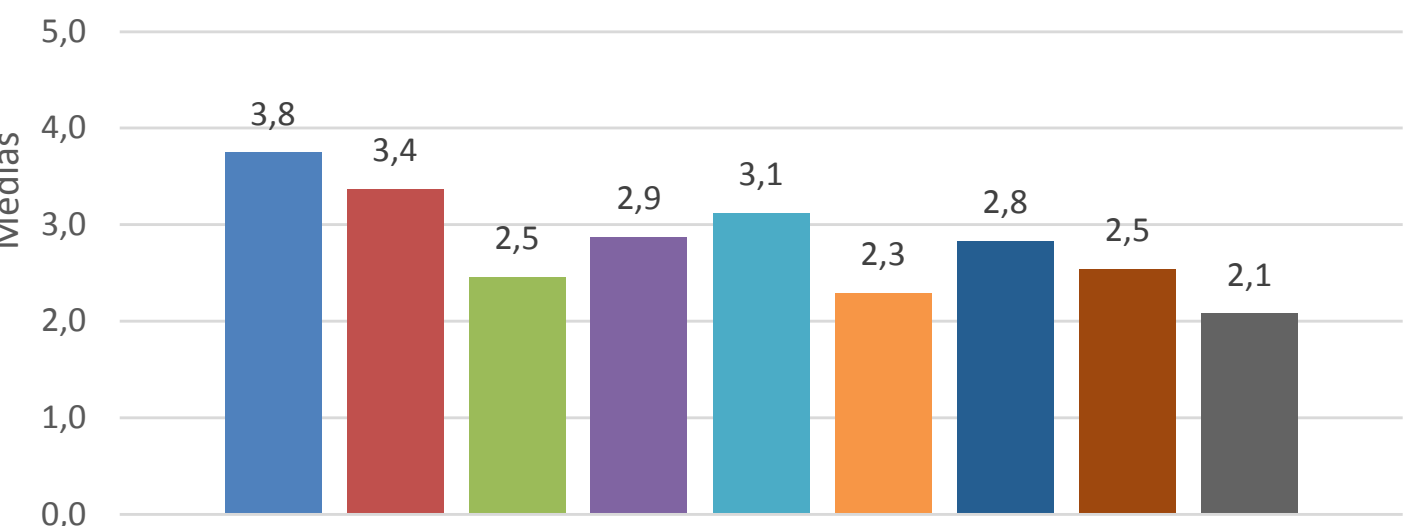

1 Os professores têm domínio sobre o conteúdo das disciplinas.

- 2 Os professores abrem espaço para discussões e fomentam a participação dos alunos.

3 Os professores têm didática.

4 Os professores estavam familiarizados com as matérias apresentadas pelos demais.

5 Os professores foram corteses e se empenharam em transmitir os conceitos.

6 Os professores usaram de diversas estratégias didáticas.

- 7 De uma forma geral, os professores eram muito bons.

— 8 Os professores foram muito rigorosos em provas e avaliações.

- 9 Os professores mostraram-se envolvidos com o desenvolvimento dos alunos.

Gráfico 1 - Avaliação dos professores. 
para serem lembrados estão: apresentação do conteúdo de forma clara, avaliação em toda aula, slides bem-elaborados, aplicação de conceitos na prática, conteúdo na lousa de forma extremamente organizada, feedback no trabalho, convidados para mostrar na prática a aplicação dos conteúdos, clareza, paciência, humor e dedicação, preocupação com o aprendizado do aluno, trabalhos bem-elaborados e com objetivos e propostas claros, conexão entre teoria e prática, aulas com dinâmicas diferentes, estudos de caso e exemplos práticos. Tais práticas vão ao encontro dos conceitos apresentados por Cruz (2008).

A propósito das estratégias didáticas inovadoras, foram citadas: realização de grupos; promoção de situações de negociação; avaliação continuada; dinâmicas; discussão de casos; Estágio Social como algo além de um estágio, envolvendo os alunos com exemplos do terceiro setor e iniciativas de sucesso; incentivo a discussões em sala; resolução de casos em todas as aulas; simulações empresariais; trabalhos em grupo com pessoas de nacionalidades diferentes; viagens para visitar empresas. Houve ainda um aluno que indicou que os professores do curso de Administração trabalham com "slides padrão" e muito trabalho em grupo, verificando-se a falta de estratégias inovadoras.

Com relação aos professores que utilizaram estratégias vivenciais para o ensino, 64\% dos docentes foram mencionados.

\section{Conteúdo}

Levantou-se que o referido curso de Administração contribuiu para a formação pessoal e profissional dos discentes e que a capacidade analítica dos alunos melhorou durante o período cursado, destacando-se que as apresentações e discussões em sala agregaram valor ao aprendizado. Tal colocação corrobora as observações de Mello, Dutra e Oliveira (2014). Em relação à interdisciplinaridade, observou-se a falta de uma integração mais dinâmica entre as disciplinas (Gráfico 2).

Os alunos foram questionados sobre qual conteúdo poderia ser mais bem (ou mais profundamente) abordado.

Houve algumas críticas pontuais: "Foi ensinado de maneira muito generalista e básica, sem integração com as demais disciplinas". Os alunos foram questionados sobre qual conteúdo

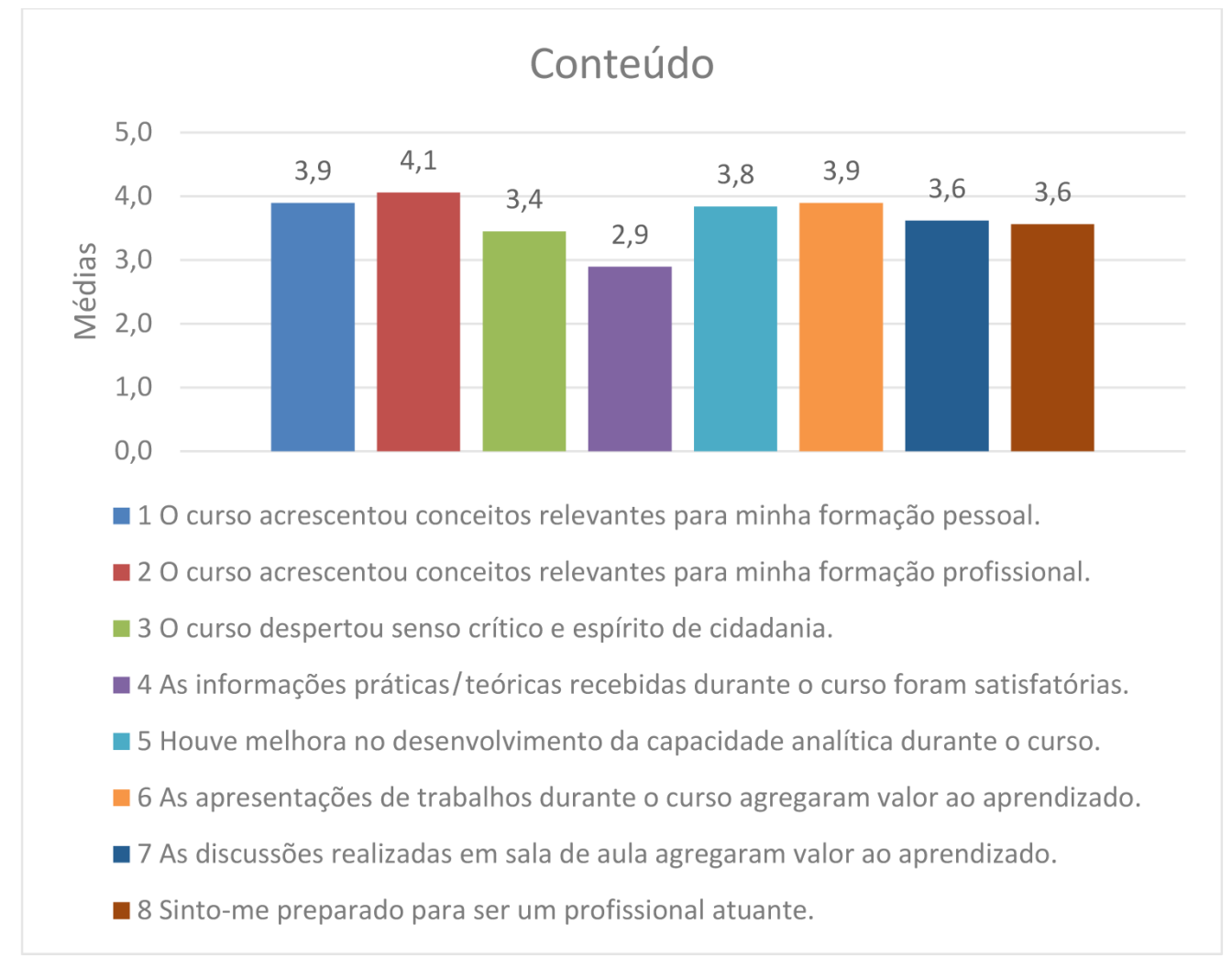

Gráfico 2 - Avaliação do conteúdo do curso. 
foi demasiadamente abordado e teceram elogios e críticas a determinadas disciplinas. Os respondentes abordaram temas que gostariam de ter visto no curso, sendo que, entre os comentários, destacou-se que poderia haver um maior preparo dos alunos para assumirem posições de liderança. Foi sugerido aprofundar os modelos de apresentação, utilizando recursos avançados do PowerPoint. Levantou-se ainda que faltaram abordagens na área de Empreendedorismo voltadas para microempresas, "pois nem todos estão interessados em trainee", tratando-se mais de temas relacionados à gestão de pequenas empresas. Foram solicitadas a abordagem de mais conceitos sobre Contabilidade e noções básicas de programação, bem como temas relacionados diretamente às empresas, visitas a "chão de fábrica" e casos de empresas.

Quanto à integração de conteúdos entre as disciplinas, houve os seguintes comentários positivos: "as disciplinas se complementaram"; "em disciplinas distintas, a integração ocorreu muito fortemente, levando-se em conta que são muitos professores diferentes que as ministram"; "as matérias de maior integração são aquelas que seguem uma mesma linha"; "foi boa, por exemplo em Contabilidade e Finanças"; "existem conteúdos em que há a integração".

Os comentários negativos foram: "não há muita integração entre os professores dos departamentos, pois os conteúdos são repetidos em matérias que deveriam ser complementares. Em uma determinada disciplina, por exemplo, parecia que em todos os semestres aprendíamos os mesmos tópicos e mesmo assim era difícil a aplicação em outras disciplinas"; "os professores, em sua maioria, assumem que os alunos não possuem conhecimentos prévios e repetem conceitos básicos ou voltam a eles"; "faltou diálogo entre os professores para uma melhor distribuição dos conteúdos entre as disciplinas oferecidas"; "ao longo da formação na faculdade, vários temas são abordados em diversas disciplinas"; "com relação a determinada disciplina, o conteúdo é ministrado por vários professores e, muitas vezes, não é assimilado, fazendo com que o docente tenha de revisar conteúdos que deveriam ter sido apreendidos"; "além disso, é uma matéria que se relaciona com diversas outras, e não se explora muito essa relação"; "a disciplina muda de acordo com o professor, ou seja, muitas vezes parece que é outra disciplina, falando de outros assuntos, quando muda o professor, e isso atrapalha muito a integração entre os conteúdos"; "a integração de conteúdos entre as disciplinas existe devido à percepção do aluno e não pelo professor".

\section{Alunos}

O Gráfico 3 mostra a parte quantitativa da visão dos alunos sobre sua própria conduta durante o curso.

Na parte qualitativa, fez-se uma abertura para os formandos tecerem sugestões de como o curso poderia otimizar a contribuição dos colegas na aprendizagem. Houve várias opiniões, e entre as principais estão:

- Trabalhos em grupo: foi proposto utilizar os grupos para realizarem projetos que exijam maior participação, que sejam feitos logo no primeiro ano, quando a maioria dos alunos tem dedicação exclusiva à universidade; trabalhos em grupo interdisciplinares e com aplicação prática mais rigorosa, para que o grupo realmente desenvolva a prática de forma global.

- Estudo de caso: realizar em sala de aula com pequenas apresentações ao final para demonstrar o que foi discutido; resoluções de casos com alunos de todos os cursos da faculdade.

Outros temas abordados foram: disciplinas integradas entre os cursos, considerando que algumas são oferecidas em todos os cursos da Faculdade, com mais debates e projetos que estimulem os alunos, ao invés de conteúdos de livros e provas, para não perder a realidade vivenciada dentro das organizações. No mesmo sentido, Santos, Anjos e Almeida (2013) se referiram à importância da reflexão dos alunos no tocante à qualidade do aprendizado.

\section{Estrutura}

O ponto básico de análise nesse processo foi com relação à maneira como as disciplinas 


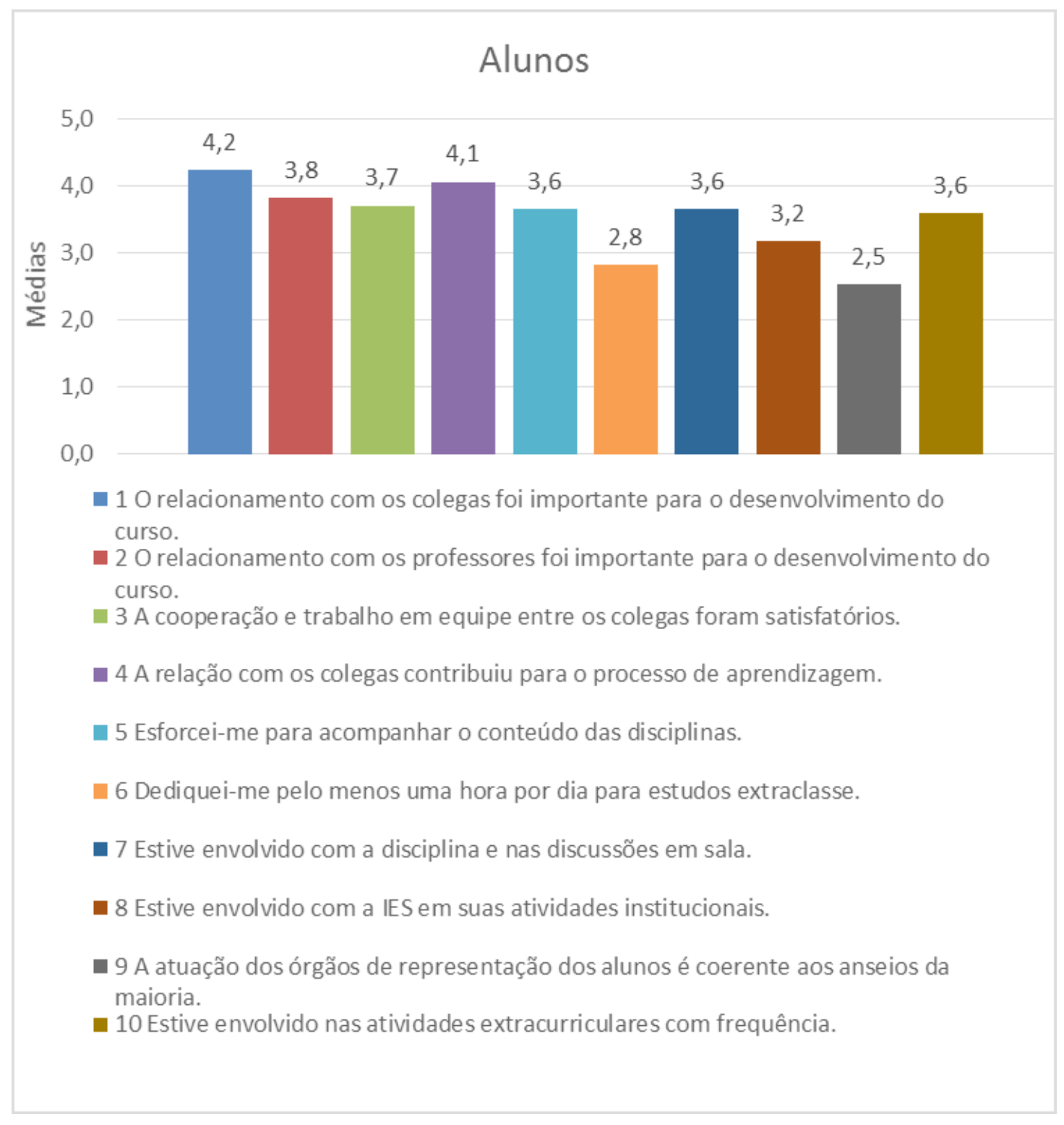

Gráfico 3 - Autoavaliação dos alunos.

estavam integradas e como o curso como um todo estava estruturado, tanto no que diz respeito ao conteúdo das disciplinas quanto em termos de carga horária destinada a cada uma delas. $\mathrm{Na}$ parte quantitativa, os aspectos explorados encontram-se no Gráfico 4.

Com relação à parte qualitativa, foi solicitado que os alunos citassem disciplinas que não estavam integradas ao currículo. Como resultado, foram mencionadas em torno de oito disciplinas. Diante disso, a coordenação do curso vem trabalhando com incentivo para que os docentes proponham alterações em programas de disciplinas, a fim de que haja maior integração entre as disciplinas, bem como que seus conteúdos sejam atualizados.
Em seguida foi pedido que os alunos citassem atividades complementares que poderiam ser oferecidas pelo curso. Em praticamente todas as respostas percebe-se o anseio por mais atividades práticas; consideram-nas fundamentais para sua formação. Foram solicitados: atividades sociais, como o Projeto Rondon; parcerias com empresas grandes e pequenas, considerando-se que os professores trouxessem os atuais problemas dessas empresas para serem resolvidos pelos alunos de acordo com a disciplina estudada; atividades e casos reais de aplicação teórica na prática; realização de visitas monitoradas e cursos de férias; mais visitas às empresas; simulação de negócios, projetos de empreendedorismo e projetos 
com a sociedade; mais palestras e incentivos para feiras de profissão.

Com relação aos problemas de estrutura que influenciaram o desenvolvimento das aulas, a maioria das reclamações discorreu sobre internet, rede e computadores. No entanto, houve ainda reclamações quanto a pouca quantidade de vagas de estacionamento, espaço pequeno para estudo individual e em grupo. Houve ainda sete comentários de alunos que não identificaram problemas com a estrutura.

Solicitou-se aos formandos que apontassem os pré-requisitos em disciplinas julgados inoportunos.
Houve cinco respostas, das quais duas apontaram para um requisito e três para outro, sendo que um deles foi analisado pela coordenação do curso e pelo departamento e deixará de ser requisito da referida disciplina. Outros quatro respondentes não encontraram problemas com pré-requisitos.

\section{Coordenação e Direção}

$\mathrm{O}$ atendimento da coordenação, secretaria e demais seções foi considerado suficiente para auxiliar os alunos. Como pode ser observado no Gráfico 5, entre as cinco questões levantadas, a

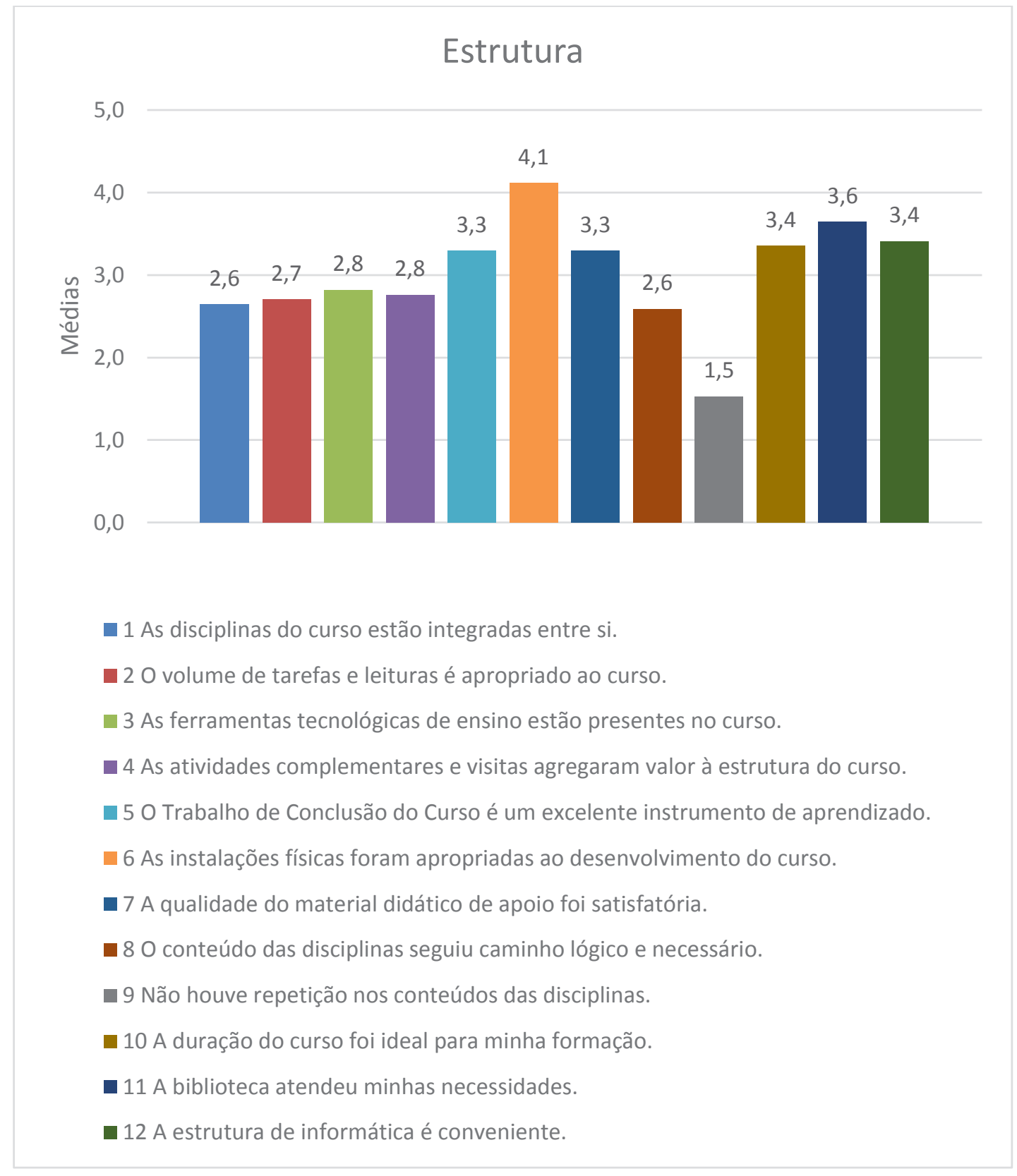

Gráfico 4 - Avaliação de itens da estrutura do curso. 
maioria obteve média acima da mediana e nenhuma abaixo.

Entre os comentários dos alunos sobre as chefias/ coordenações do curso, destacaram-se como positivos: "Achei a chefia do período sempre preocupada em solucionar os problemas dos alunos, nunca impondo burocracia ou impedimentos quando estava em seu alcance colaborar"; "As chefias/coordenações do curso estão dentro do esperado, executando bem as suas funções". Um dos respondentes comentou que a coordenação "muda muito" e, com isso, há pouco tempo para implementar as mudanças. Entre os comentários negativos houve um citando que a coordenação deve atender os pedidos dos alunos referentes à insatisfação com professores. Outros dez respondentes citaram não ter comentários ou pouco contato com as chefias/coordenações.
Quanto à qualidade do ensino, como se pode observar nos gráficos a seguir, um percentual bastante elevado sente-se satisfeito com o curso: $62 \%$ dos formandos que responderam esta pesquisa reconhecem que o mesmo atendeu suas expectativas (Gráfico 6), e 56\% fariam o curso novamente (Gráfico 7-A). Outro fato a ser destacado é que 75\% escolheriam a mesma Faculdade se pudessem voltar ao passado (Gráfico 7-B). Como observado por Lousada e Martins (2005), deve-se dar todo o apoio para que os diplomados estejam aptos para o exercício profissional.

Quanto aos comentários gerais sobre o curso, houve diversas abordagens tanto positivas quanto negativas. Entre as positivas estão: "o curso foi uma grande experiência de vida"; "tanto o curso quanto a grade curricular são bons"; "não me

\section{Coordenação e Direção}

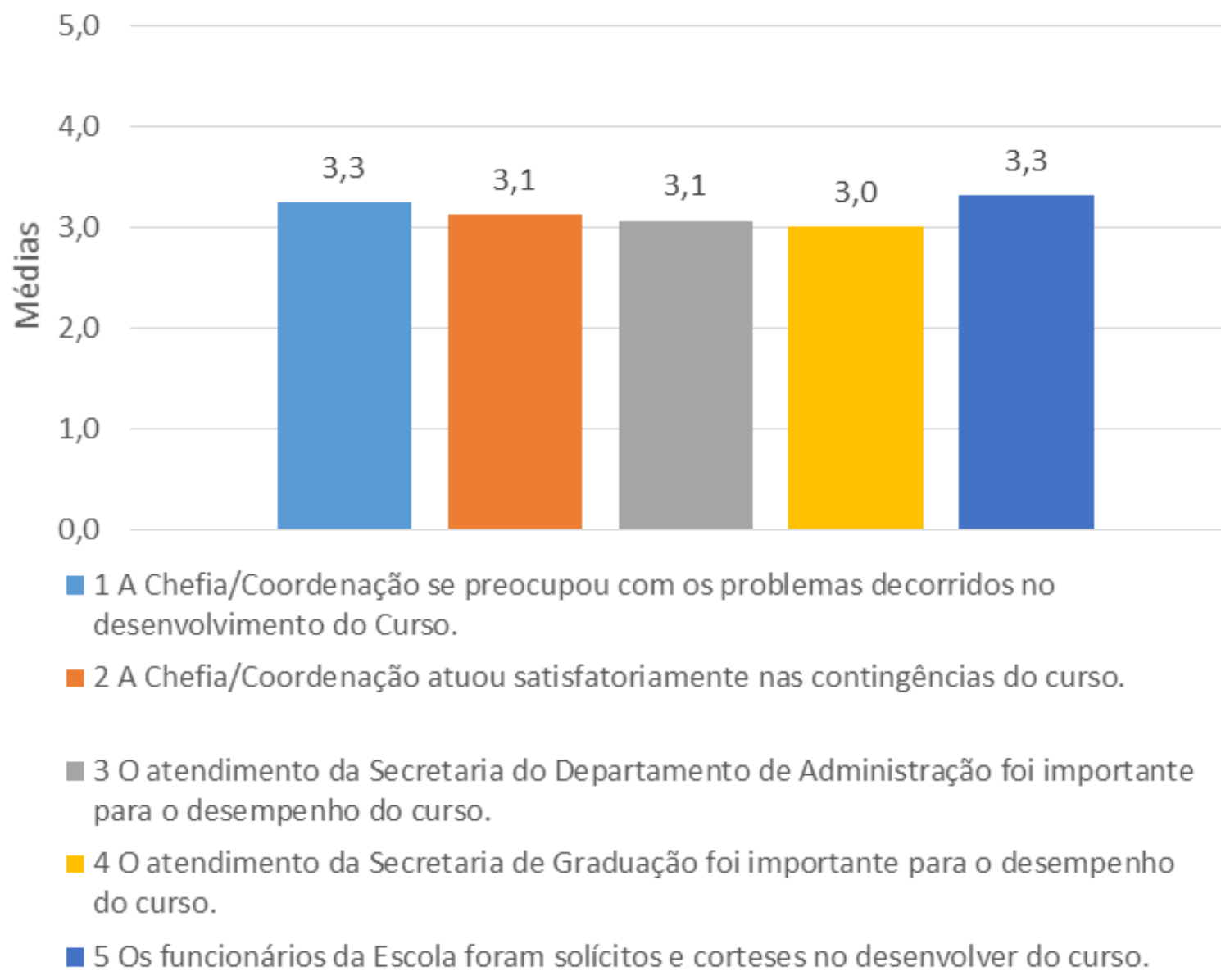

Gráfico 5 - Avaliação da Coordenação e Direção. 
arrependo de tê-lo feito, pois me sinto muito bem formado para o mercado de trabalho, principalmente devido aos bons resultados em processos de trainee"; "há nitidamente um grupo de professores muito comprometidos com a qualidade da Faculdade e o aprendizado e desenvolvimento dos discentes"; "o curso no geral atendeu a algumas expectativas"; "eu me desenvolvi mais nas atividades extracurriculares do que propriamente durante o curso de graduação, mas o curso foi um grande apoio para que essas atividades fossem desenvolvidas"; "é do mesmo nível da universidade de Roma que cursei"; "foi essencial não apenas para minha formação profissional, mas também para minha formação como cidadão"; "o curso em geral é bem estruturado com a teoria".

Entre as negativas: "não fui preparado para assumir posições de liderança"; "é necessário que os professores cobrem mais os alunos, com provas difíceis, porém, para que a matéria seja cobrada, ela deve ser, com certeza, muito bem explicada e desenvolvida em sala de aula"; "o curso precisa melhorar no que diz respeito à parte prática, os estudos de caso não são a realidade, ele é teórico, assim como as aulas"; "conteúdos e matérias importantes não receberam relevância ou tiveram um critério de avaliação muito fraco"; "o curso em geral não agradou"; "o curso não atendeu as minhas expectativas"; "precisa ser mais prático e expor o aluno a mais desafios que ele possa encontrar no mercado de trabalho".

Foram apresentadas algumas sugestões: "que a IES faça parcerias com empresas de grande e pequeno porte, e que os alunos possam ir até essas empresas, diagnosticar os problemas e resolvê-los em sala de aula"; "os professores deveriam ser mais rígidos"; "os trabalhos práticos são essen-

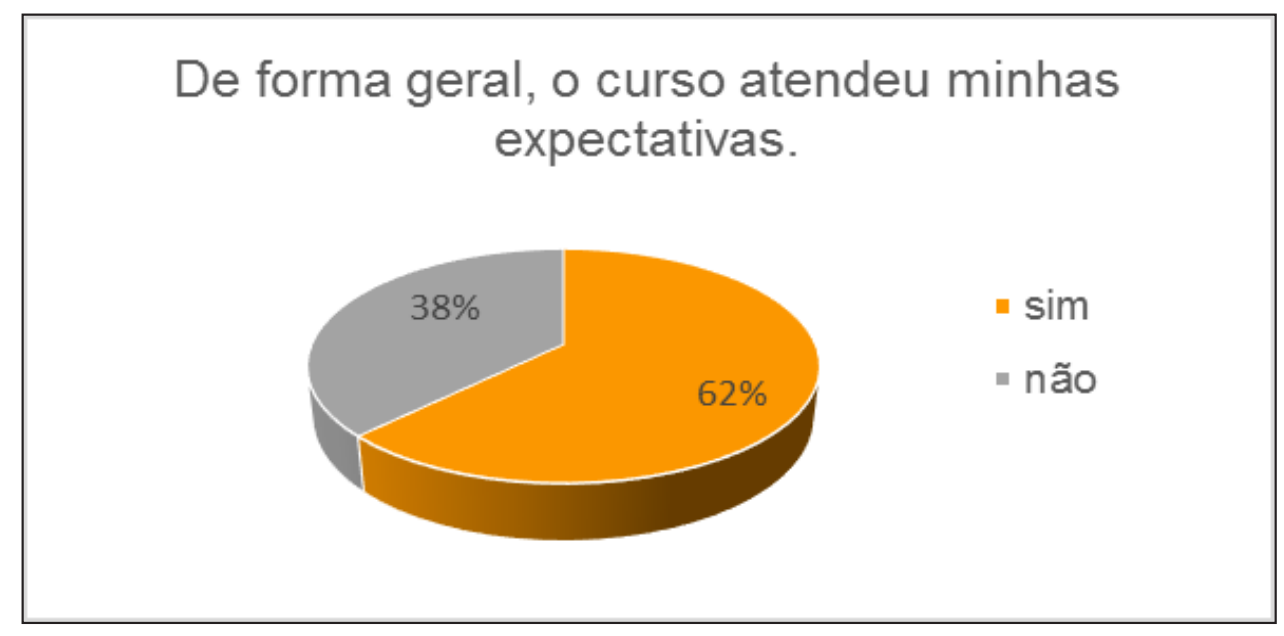

Gráfico 6 - Avaliação da expectativa dos alunos em relação ao curso.

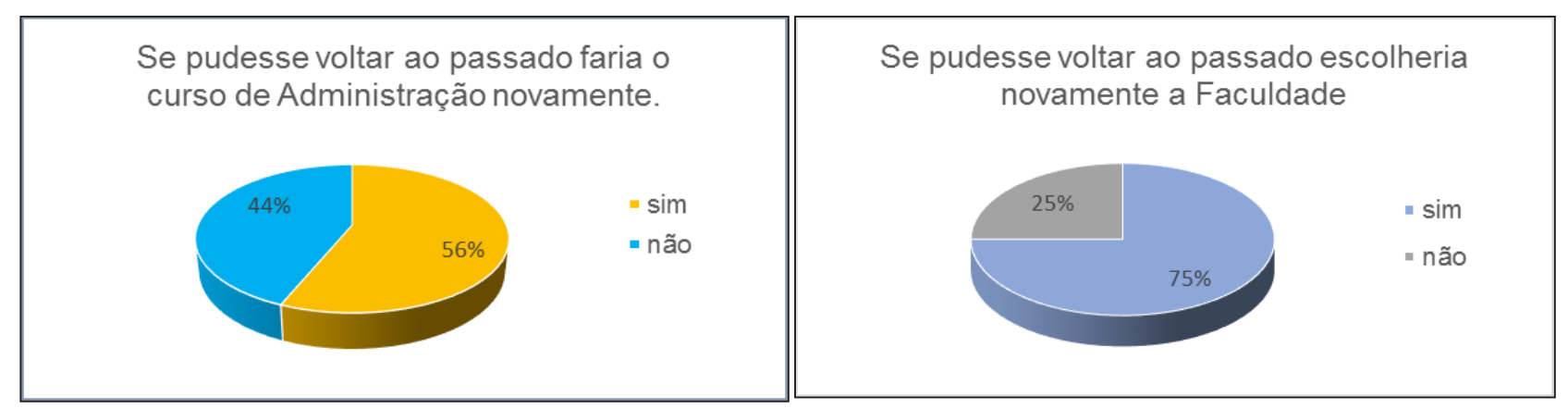

Gráfico 7 - Respostas dos alunos em relação à escolha do curso (A) e da Faculdade (B). 
ciais, muitos deles foram realmente interessantes"; "melhorar a alocação de professores e se alinhar com conteúdo que corresponda ainda mais à realidade do mercado atual, a universidade tem espaço para ser de fato excelente"; "um ponto a melhorar é a internacionalização da faculdade, com mais convênios e bolsas de estudos, a fim de viabilizar para os discentes a oportunidade de estudar no exterior".

\section{Considerações Finais}

Com o intuito de investigar a satisfação dos egressos de um curso de graduação em Administração de uma universidade pública do Estado de São Paulo, este estudo, de caráter quali-quantitativo, coletou dados por meio de questionário aplicado a alunos.

Considerando-se que a avaliação da satisfação é um dos principais pontos para o progresso contínuo das organizações, ao mensurar as percepções e experiências vividas pelo corpo discente, é possível adquirir informações significativas que poderão embasar decisões futuras que permitam a melhoria da qualidade do serviço oferecido pela instituição.

Os resultados demonstram que há alta capacidade e domínio do conteúdo das disciplinas por parte dos docentes, com oportunidades para discussão; no entanto, sob o olhar discente, para muitos ainda faltam didática e estratégias inovadoras.

Observou-se ainda que, na média, o envolvimento de docentes com os alunos é relativamente baixo, algo que, por sua vez, não impede a contribuição daqueles para a formação pessoal e profissional destes, bem como a melhoria da capacidade analítica dos graduandos no decorrer do curso.

A interdisciplinaridade foi apontada como item relevante, bem como a importância de se aprimorar o relacionamento entre docentes e alunos para o desenvolvimento do curso.

Uma vez que os alunos sentem a necessidade de aulas mais dinâmicas, expressivas e de conteúdo atualizado, é válido atentar para tal demanda e, adequando-se propostas interessantes aos princípios educacionais que abrangem o ensino superior, consequentemente se obtêm ganhos relevantes para a educação.
Os formandos, ao sugerirem estratégias para a contribuição dos próprios colegas na aprendizagem, apontaram, entre as principais opiniões, os trabalhos em grupo e estudo de casos, táticas que são bastante utilizadas nas disciplinas, pois há, inclusive, algumas disciplinas optativas de "estudo de casos" em diversas áreas abordadas no curso.

Foram apontadas algumas disciplinas com falta de integração ao currículo. Diante disso, a coordenação do curso iniciou um trabalho junto aos docentes para uma revisão nos programas das disciplinas, especificamente nas que foram indicadas pelos respondentes.

Entre as atividades complementares, em todas as questões que abordaram o assunto, foi possível perceber a necessidade de mais atividades práticas, que os alunos consideram fundamentais para sua formação.

Nesse contexto, a chefia e a coordenação do curso foram bem avaliadas, mostrando-se, na opinião dos alunos, frequentemente preocupadas em resolver os problemas dos alunos, e buscando desburocratizar procedimentos o máximo possível, o que influencia positivamente a relação entre instituição e aluno.

Conclui-se que o curso de graduação agregou valores aos alunos egressos, de modo a que contribuiu para a formação social e intelectual deles. O resultado da pesquisa demonstra que os estudantes se tornaram seres mais reflexivos e dispostos a desenvolver na prática o conhecimento adquirido.

A didática foi ressaltada pelos alunos, com críticas e sugestões que demonstraram a necessidade de sempre mensurar a satisfação dos formandos do curso de graduação, com o objetivo de desenvolver ações estratégicas de melhoria no ensino, com vistas a suprir as expectativas dos estudantes.

\section{Referências Bibliográficas}

GRUZ, J. M. O. "Processo de Ensino-Aprendizagem na Sociedade da Informação". Educaşão \& Sociedade, Campinas, vol. 29, n. 105, set./dez. 2008, pp. 1023-1042.

LOUSADA, A. G. Z. \& MARTINS, G. A. "Egressos como Fonte de Informação à Gestão dos Cursos de Ciências Contábeis". Revista Contabilidade e Financas USP, São Paulo, n. 37, jan./abr. 2005, pp. 73-84. 
MAINARDES, E. W. \& DOMINGUES, M. J. C. S. "Avaliação da Qualidade de Atributos Específicos de Instituições de Ensino Superior em Cursos Privados de Administração em Joinville, SC". Organizações \& Sociedade, Salvador, vol. 18, n. 58, jul./set. 2011, pp. 429-444.

MELLO, S. C. B.; DUTRA, H. F. O.; OLIVEIRA, P. A. S. "Avaliando a Qualidade de Serviço Educacional numa IES: o Impacto da Qualidade Percebida na Apreciação do Aluno de Graduação". Organizações \& Sociedade, vol. 8, n. 21, maio/ago. 2001, pp. 125-137.
SANTOS, V. C.; ANJOS, K. F.; ALMEIDA, O. S. "A Percepção de Formandos sobre a Pesquisa em Enfermagem no Curso de Graduação". Revista de Enfermagem da UFSM, vol. 3, n. 1, jan./abr. 2013, pp. 144-154.

SOUZA, C. G. M.; SILVA, D.; MORETTI, S. L. A.; GARCIA, M. N. "Construção e Validação de Escala de Qualidade de Ensino e Serviços: um Estudo com Alunos de Cursos de Graduação em Administração de Empresas". Rege, São Paulo, vol. 21, n. 1, jan./mar. 2014, pp. 65-82.

Publicado em 11/11/2016. 